- Improves reader awareness of barriers to dental attendance and the importance of cost to the patient of a dental examination.

- Patients' attendance patterns might be masked by methods of data presentation.

- Provides a method to obtain a continuous data set and a method to measure the possible effect of charges unconfounded by availability of dentists.

\title{
The relationship between NHS patient charges and the uptake of dental examinations by Scottish adults 1982-1998
}

\author{
S. Lacey ${ }^{1}$
}

\begin{abstract}
Objective The aim of this study was to determine if increasing cost to the patient of an NHS dental examination was associated with a change in the uptake of dental examinations by Scottish adults aged 18 years and over. The null hypothesis was that there was no significant difference $(a=0.05)$ in the number of NHS dental examinations taken up by Scottish adults with increase in cost to the patient.

Method Data for this retrospective study of cost and dental attendance between 1982-1998 was collected from the British Dental Association and Scottish Dental Practice Division. The number of examinations per month per dentist was calculated for the years 1982-1998 as an indicator of dental attendance.

Results The reported number of NHS dental examinations increased by 34\% between 1982 and 1998 from 1,564,330 to 2,099,944. However the reported number of general dental practitioners working in the NHS in Scotland increased by $48 \%$ from 1,362 to 2,012. The number of examinations per month per dentist decreased from 95.71 in 1982 to 86.98 in 1998.

Conclusion There was a significant $(p=0.001)$ reduction of $7.6 \%$ in the number of examinations per month per dentist after the introduction of charges. However within the charged data, while there is still a reduction, it was not significant. Other cost related factors may be influencing dental attendance and should be considered.
\end{abstract}

\section{INTRODUCTION}

The oral health benefits of regular dental attendance are well documented. Levels of total tooth loss and untreated caries are reducing in those who attend regularly. ${ }^{1}$ Chronic severe periodontal conditions are worse in those who have not attended the dentist regularly. Regular dental attendance has also been found

\footnotetext{
${ }^{1 *}$ Honorary Visiting Research Fellow, Dental Institute, King's College London, Biomaterials and Conservative Dentistry, Floor 25 Guy's Tower, Guy's Hospital, London, SE1 9RT *Correspondence to: Dr Susanna Lacey

Email:susanna.lacey@kcl.ac.uk
}

\section{Refereed paper}

Accepted 29 November 2005

DOI: $10.1038 /$ sj.bdj.4814012

() British Dental Journal 2006; 201: 361-364 to be associated with reduced levels of dental anxiety in Scottish schoolchildren. ${ }^{2}$ However, in 1988, 22\% of a large sample of UK adults stated that the cost of treatment was an important barrier to dental attendance. ${ }^{3}$ Oral health inequalities have been demonstrated within the UK and also in Scotland. ${ }^{1}$ It has been shown that those whose oral health status could be improved by more regular attendance are also those who considered cost a barrier to dental attendance. ${ }^{3}$ In an earlier Scottish study, carried out between 1962 and 1981, it was found that patients' charges were associated with a reduced demand for dental care but that other factors such as the availability and accessibility of dentists had a greater effect on numbers attending for dental examinations. ${ }^{4}$

Patient charges for dental examinations were introduced in 1990 and the number of dentists practising in Scotland has increased in recent years. It was considered useful to re-examine the relationship between cost and the uptake of dental treatment within the NHS in Scotland. In the first instance it was decided to consider dental attendance and the cost to the patient of a dental examination.

\section{METHOD}

Figures for the number of examinations of Scottish adults (Table 1) and the number of dentists practising within the NHS in Scotland (Table 2) were obtained from the Scottish Dental Practice Board. The study period 1982-1998 saw the introduction of continuing care and capitation schemes, the introduction of the new GP17 form with various examination categories and a change in presentation of data from calendar years to financial years. This represented a challenge in continuity when collecting the figure for yearly examinations. From 1982 until September 1990, the total number of examinations included normal and trauma examinations. From October 1990, the total included clinical, extensive clinical, full case assessment and treatment summary. Between October 1990 and March 1991, data was presented on both old and new forms and added together to give the total number of examinations for this period.

Because of the differing examination categories and for continuity with unpublished data prior to 1989 and subsequent published data, it was decided to confine this study to all Scottish adults aged 18 years and over in both the exempt and 


\begin{tabular}{|c|c|c|c|}
\hline \multicolumn{2}{|c|}{ Interval } & \multirow{2}{*}{$\begin{array}{c}\text { Months } \\
12\end{array}$} & \multirow{2}{*}{$\begin{array}{c}\begin{array}{c}\text { Total } \\
\text { Examination }\end{array} \\
1,564,330\end{array}$} \\
\hline Jan-Dec & 1982 & & \\
\hline Jan-Dec & 1983 & 12 & $1,617,970$ \\
\hline Jan-Dec & 1984 & 12 & $1,669,324$ \\
\hline Jan-Dec & 1985 & 12 & $1,612,167$ \\
\hline Jan-Dec & 1986 & 12 & $1,682,928$ \\
\hline Jan-Dec & 1987 & 12 & $1,716,367$ \\
\hline Jan-Dec & 1988 & 12 & $1,767,954$ \\
\hline Jan-Dec & 1989 & 12 & $1,773,167$ \\
\hline Jan-Sept & 1990 & 9 & $1,299,261$ \\
\hline Oct-Mar* & 1990-91 & 6 & 859,240 \\
\hline April-Mar & $1991-92$ & 12 & $1,900,315$ \\
\hline April-Mar & $1992-93$ & 12 & $1,930,598$ \\
\hline April-Mar & $1993-94$ & 12 & $1,934,955$ \\
\hline April-Mar & 1994-95 & 12 & $1,954,884$ \\
\hline April-Mar & 1995-96 & 12 & $1,929,461$ \\
\hline April-Mar & $1996-97$ & 12 & $1,868,633$ \\
\hline April-Mar & $1997-98$ & 12 & $2,125,818$ \\
\hline April-Mar & $1998-99$ & 12 & $2,099,944$ \\
\hline
\end{tabular}

*The figure for October 1990 to March 1991 is obtained by adding data from the old dental form and new dental form

\begin{tabular}{|c|c|c|c|c|}
\hline Date & Principals & Assistants & $\begin{array}{c}\text { Vocational } \\
\text { trainees } \\
\end{array}$ & Total dentists \\
\hline 1982 & 1,334 & 28 & - & 1,362 \\
\hline 1983 & 1,379 & 28 & - & 1,407 \\
\hline 1984 & 1,425 & 24 & - & 1,449 \\
\hline 1985 & 1,392 & 21 & - & 1,413 \\
\hline 1986 & 1,456 & 23 & - & 1,479 \\
\hline 1987 & 1,511 & 22 & - & 1,533 \\
\hline 1988 & 1,528 & 21 & 26 & 1,575 \\
\hline 1989 & 1,587 & 20 & 44 & 1,651 \\
\hline 1990 & 1,626 & 19 & 46 & 1,691 \\
\hline 1991 & 1,656 & 17 & 67 & 1,740 \\
\hline 1992 & 1,680 & 27 & 60 & 1,767 \\
\hline 1993 & 1,774 & 30 & 74 & 1,878 \\
\hline 1994 & 1,770 & 36 & 76 & 1,882 \\
\hline 1995 & 1,776 & 44 & 83 & 1,903 \\
\hline 1996 & 1,767 & 49 & 80 & 1,896 \\
\hline 1997 & 1,802 & 65 & 84 & 1,951 \\
\hline 1998 & 1,855 & 62 & 95 & 2,012 \\
\hline
\end{tabular}

non-exempt categories. The exempt categories in the British National Health Service comprise pregnant and nursing mothers and those adults aged 19 years in full time education. There are other categories of patients who are not exempt but whose charge is borne by the Department of Social Security. These comprise the unemployed, those on low incomes receiving income support or family credit, and those on disability benefit. Some of the pre-1991 data included categories of 16-18 year olds (dentures-school exemption, not exempt, expectant and nursing mothers). These
Table 3 Patients' charges for NHS dental examination 1982-1998

\begin{tabular}{|c|c|c|c|}
\hline $\begin{array}{l}\text { Date of price } \\
\text { change }\end{array}$ & Fee $(€)$ & $\%$ of dentists' fee & $\begin{array}{l}\text { Patients' } \\
\text { charge }(€)\end{array}$ \\
\hline October 1982 & 2.27 & 0 & 0 \\
\hline October 1983 & 2.40 & 0 & 0 \\
\hline October 1984 & 2.53 & 0 & 0 \\
\hline October 1985 & 3.00 & 0 & 0 \\
\hline October 1986 & 3.50 & 0 & 0 \\
\hline October 1987 & 3.90 & 0 & 0 \\
\hline October 1988 & 4.20 & 75 & 3.15 \\
\hline October 1989 & 4.60 & 75 & 3.45 \\
\hline October 1990 & 4.60 & 75 & 3.45 \\
\hline June 1991 & 5.00 & 75 & 3.75 \\
\hline July 1992 & 4.60 & 75 & 3.45 \\
\hline April 1993 & 4.60 & 80 & 3.68 \\
\hline January 1994 & 4.75 & 80 & 3.80 \\
\hline April 1994 & 4.90 & 80 & 3.92 \\
\hline April 1995 & 5.00 & 80 & 4.00 \\
\hline April 1996 & 5.15 & 80 & 4.12 \\
\hline December 1996 & 5.20 & 80 & 4.16 \\
\hline April 1997 & 5.30 & 80 & 4.24 \\
\hline December 1997 & 5.40 & 80 & 4.32 \\
\hline April 1998 & 5.65 & 80 & 4.52 \\
\hline
\end{tabular}

were divided by three to give an approximation of the number of examinations for 18 year olds in these categories.

Figures for the costs and patient contributions for dental examinations (Table 3) were obtained from the British Dental Association. As the change in examination costs occurred at different times in the year and in some years twice in the same year, the average cost for the year was calculated (Table 4).

The number of examinations per month per dentist was calculated and these values were compared with the figures for the average cost to the patient of a dental examination (Table 4). The data was analysed using Regression Analysis for 1982-1998 data (Genstat 5, Edinburgh University Computing Services) and Restricted Regression Analysis for the charged data 1988-1998 (Genstat 5 EUCS).

Data were grouped into three categories of number of examinations per month (80-85, 86-90 and 91-96) and three categories of mean examination cost to the patient ( $£ 0-£ 1.99, £ 2-£ 3.99$ and $£ 4$ and over). The $3 \times 3$ grouped data (Table 5) were analysed with Fisher's Exact Test (StatExact, Cytel Statistical Software, Cambridge, MA, USA).

The difference in means between charged and uncharged data was calculated as a percentage.

\section{RESULTS}

Between 1982 and 1998, the number of examinations per month per dentist reduced from 95.71 in 1982 to 86.98 in 1998, while the mean cost to the patient of an examination rose from zero in 1982 to $£ 4.49$ in 1998 (Table 1, Fig. 1 and Fig. 2). There was a significant $(p=0.001)$ association between the examinations per month per dentist and the cost to the patient of an examination (ANOVA, Genstat 5, EUCS). However when the regression analysis was repeated for the restricted period 1988-1998, when there were charges to the patient, then the results were not significant ( $p=0.317)$. For the grouped data, Fisher's exact test gave an asymptotic p-value of 0.024 and an exact p-value of 0.0039 (Table 5). 


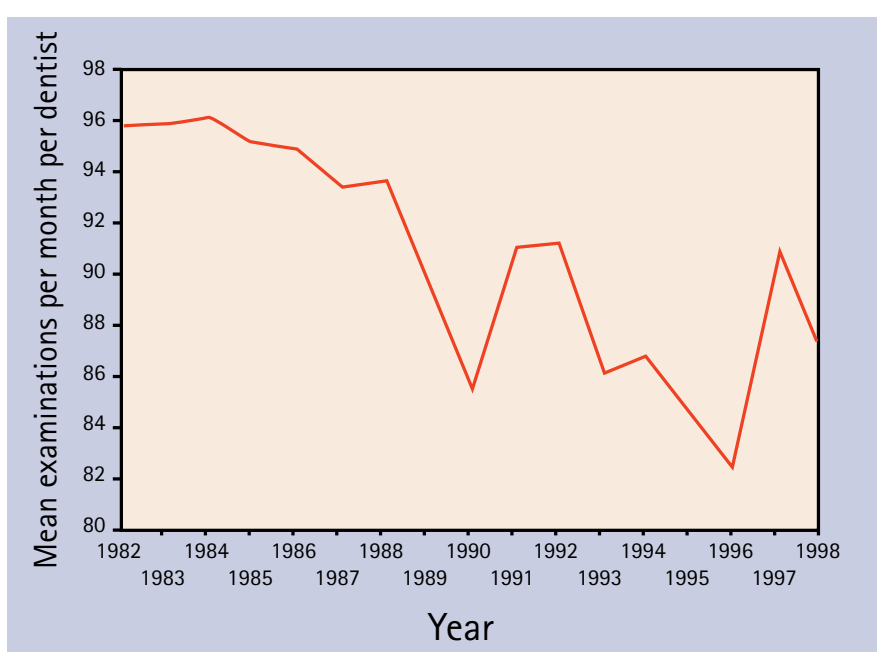

Fig. 1 Examinations per month per dentist from 1982-1998

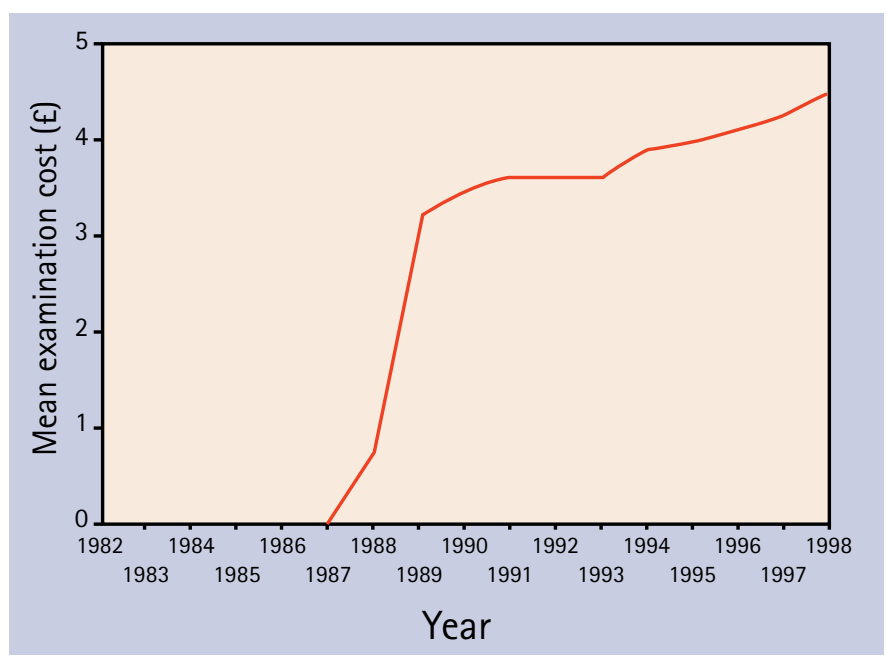

Fig. 2 Mean examination cost from 1982-1998

The difference in means of dental attendance between charged and uncharged data showed a reduction of 7.6\%.

\section{DISCUSSION}

Between 1982 and 1998 the total number of examinations of Scottish adults has increased from 1,564,330 in 1982 to 2,106,413 in 1998.

Although the total number of examinations in Scotland is increasing, the number of examinations per month per dentist is falling. The extent of this fall is still small but it would be interesting to speculate what level of price increase would be prohibitive and produce a large reduction in the examinations per month per dentist. As the restricted regression analysis has not produced a significant result, it would be unwise to predict at what point there would be a large reduction.

This study has been limited to initial contacts, ie dental examinations. Charges for other items of service were introduced not long after the beginning of the health service and have therefore been in operation for a considerable time. Further study of the effect of cost on treatment choice might reveal larger reductions in the numbers of certain items for example root treatments and crowns.

We have seen that those groups most in need of improvement in oral health are those who have selected cost as a reason for non-attendance. ${ }^{3}$ Anxiety and fear are still major barriers to dental attendance and it has been shown that reduction in anxiety might be associated with more regular attendance. ${ }^{3}$ Gradual increase in cost, by gradually reducing attendance, could in turn

\begin{tabular}{|c|c|c|c|}
\hline Interval & Months & $\begin{array}{l}\text { Examinations/ } \\
\text { month/dentist }\end{array}$ & $\begin{array}{c}\text { Mean examination } \\
\text { cost }(€)\end{array}$ \\
\hline Jan-Dec 1982 & 12 & 96 & 0 \\
\hline Jan-Dec 1983 & 12 & 96 & 0 \\
\hline Jan-Dec 1984 & 12 & 96 & 0 \\
\hline Jan-Dec 1985 & 12 & 95 & 0 \\
\hline Jan-Dec 1986 & 12 & 95 & 0 \\
\hline Jan-Dec 1987 & 12 & 93 & 0 \\
\hline Jan-Dec 1988 & 12 & 94 & 0.79 \\
\hline Jan-Dec 1989 & 12 & 90 & 3.23 \\
\hline Jan 1990-Mar 1991 & 15 & 85 & 3.45 \\
\hline April 1991-Mar 1992 & 12 & 91 & 3.63 \\
\hline April 1992-Mar 1993 & 12 & 91 & 3.60 \\
\hline April 1993-Mar 1994 & 12 & 86 & 3.62 \\
\hline April 1994-Mar 1995 & 12 & 87 & 3.89 \\
\hline April 1995-Mar 1996 & 12 & 84 & 3.98 \\
\hline April 1996-Mar 1997 & 12 & 82 & 4.09 \\
\hline April 1997-Mar 1998 & 12 & 91 & 4.23 \\
\hline April 1998-Mar 1999 & 12 & 87 & 4.49 \\
\hline
\end{tabular}

Table $53 \times 3$ grouped mean examination cost and grouped examinations per month per dentist

\begin{tabular}{|c|c|c|c|c|}
\hline \multirow[t]{2}{*}{$\begin{array}{l}\text { Examinations per } \\
\text { month per dentist }\end{array}$} & \multicolumn{3}{|c|}{ Mean Examination Cost to Patient } & \multirow[b]{2}{*}{ TOTALS } \\
\hline & $€ 0-£ 1.99$ & $£ 2-£ 3.99$ & $£ 4$ and over & \\
\hline $80-85$ & 0 & 3 & 1 & 4 \\
\hline $86-90$ & 0 & 2 & 2 & 4 \\
\hline $91-96$ & 7 & 2 & 0 & 9 \\
\hline TOTALS & 7 & 7 & 3 & 17 \\
\hline Fisher Statistic & 11.2 & & & \\
\hline d.f. & 4 & & & \\
\hline Asymptotic $p$-value & 0.024 & & & \\
\hline Exact $p$-value & 0.0039 & & & \\
\hline
\end{tabular}

produce an increase in dental anxiety, thus perpetuating the cycle of non-attendance and a reduction in oral health status. As our aim should be to improve the oral health status of the population, we should be attempting to remove or at least minimise the effect of cost as a barrier to dental attendance. A target was set that less than $10 \%$ of $45-54$ year olds in Scotland would be without their own teeth in 2000. ${ }^{5}$ However in 1998 almost 20\% of Scottish adults in this age group were still edentulous. ${ }^{6}$ It is possible that cost may be a factor in patients' treatment choice.

There are other factors which could be influencing dental attendance. The factors related to cost include:

a) cost of living as indicated by retail price index

b) levels of employment

c) average earnings.

Factors related to the numbers attending depend on the count and age distribution of the adult population. While the population of Scotland during the experimental period was gradually decreasing, the numbers of adults 18 years and over is increasing. Further study of these factors will enable better understanding of the effect of cost related barriers on dental attendance.

There may be other factors contributing to numbers attending which are not related to cost. Levels of education and perceived 
need for dental treatment are included in barriers to dental attendance. ${ }^{3}$ The move of many dentists from NHS to private practice may affect the numbers attending for NHS examinations.

\section{CONCLUSION}

While it cannot be assumed that there is a direct relationship or causal effect of cost on dental attendance, it has been shown that there has been a significant reduction in dental attendance of Scottish adults in the NHS with the introduction of patient charges. The null hypothesis, that there is no difference in the uptake of dental examinations by Scottish adults 18 years and over with the introduction of charges, can be rejected. The difference in attendance amounts to a reduction of $7.6 \%$.

This article forms part of a dissertation submitted in partial fulfilment for the degree of MSc at the University of Edinburgh. The author is indebted to her supervisor Professor Philip Sutcliffe of Edinburgh Postgraduate Dental Institute. The author would like to acknowledge the assistance of Bill Adams and Thorsten Forster at the Medical Statistics Unit, Department of Public Health, University of Edinburgh.

1. Todd J, Lader D. Adult Dental Health 1988, United Kingdom. London: HMSO Office of Population Censuses and Surveys, Social Survey Division, 1991.

2. Bedi R, Sutcliffe P, Donnan P T, McConnachie J. The prevalence of dental anxiety in a group of 13- and 14-year old Scottish school children. Int J Paediatr Dent 1992; 2:17-24.

3. Finch H, Keegan J, Ward K, Sen S B. Barriers to the receipt of dental care, a qualitative study. London: Social and Community Planning Research, 1988.

4. Parkin D, Yule B. Patient charges and the demand for dental care in Scotland, 196281. Appl Econ 1985; 20: 229-242.

5. The Scottish Office Department of Health. Scotland's health - a challenge to us all. pp 5. London: HMSO, 1995.

6. Nuttall N, Steele J G, Nunn J et al. A guide to the UK Adult Dental Health Survey 1998. pp 3. London: British Dental Association, 2001. 